\title{
Editorial -Time for an experiment
}

This issue of the journal contains six very different papers exploring the issues around the use of learning technologies, which reflect the growing diversity of research interests and activities in this area. Oliver, Bradley and Boyle describe a project that is concerned with the development of online courses as part of a pan-European virtual university. The issues raised by the paper are timely given the current national initiative to develop a UK euniversity. McSporran and Young consider the impact of gender issues on online learning and contend that there is evidence to suggest that women achieve better results than men and that it is the loner male that is disadvantaged by distance learning. Condron reports on a TLTP (Teaching and Learning Technology Programme) 3 project and in particular on the use of electronic resources to support dialogue in small-group teaching. Campbell, Littlejohn and Duncan also look at resources but from the perspective of encouraging the reuse of academic resources as part of an initiative to develop a Scottish electronic staff development library. Shaikh and Macaulay report on a study of the use of groupware to support collaborative learning. Finally, Davies and Denning identify six conceptual areas which they suggest are of relevance and significance for online behaviour.

In this issue we would like to break with tradition and try an experiment. We invite you to give comment on the Davies and Denning paper. In the next issue we will print a synthesis of your reflections, along with a response from the authors. All comments should be sent by email to g.conole@bristol.ac.uk by 18 September.

Gráinne Conole

Deputy Editor 